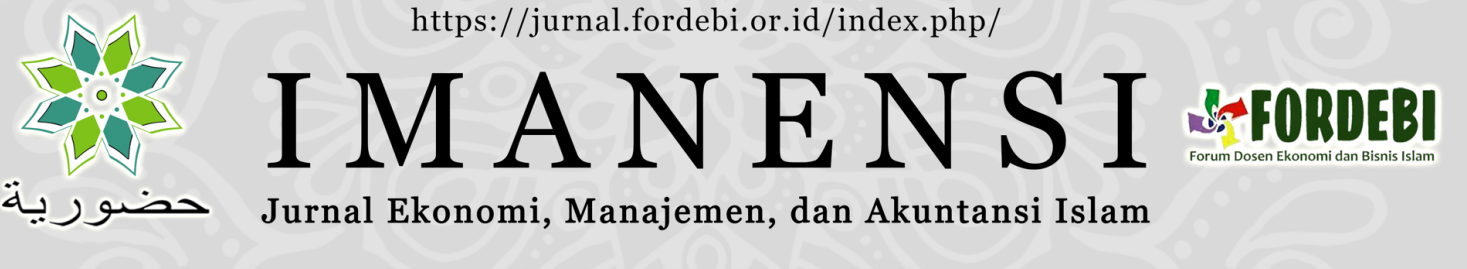

\title{
TUJUAN AKUNTANSI PERTANIAN BERBASIS FILOSOFI RANGKIANG
}

\author{
Khadijah Ath Thahiraha,1*, Dedi Fernandab,2 \\ $a, b$ Universitas Dharma Andalas, J, Sawahan No. 103 A, Simpang Haru, Padang, 25000, Indonesia \\ 1 khadijahattairah@yahoo.com*; 2 dedifernanda@gmail.com \\ * Corresponding author
}

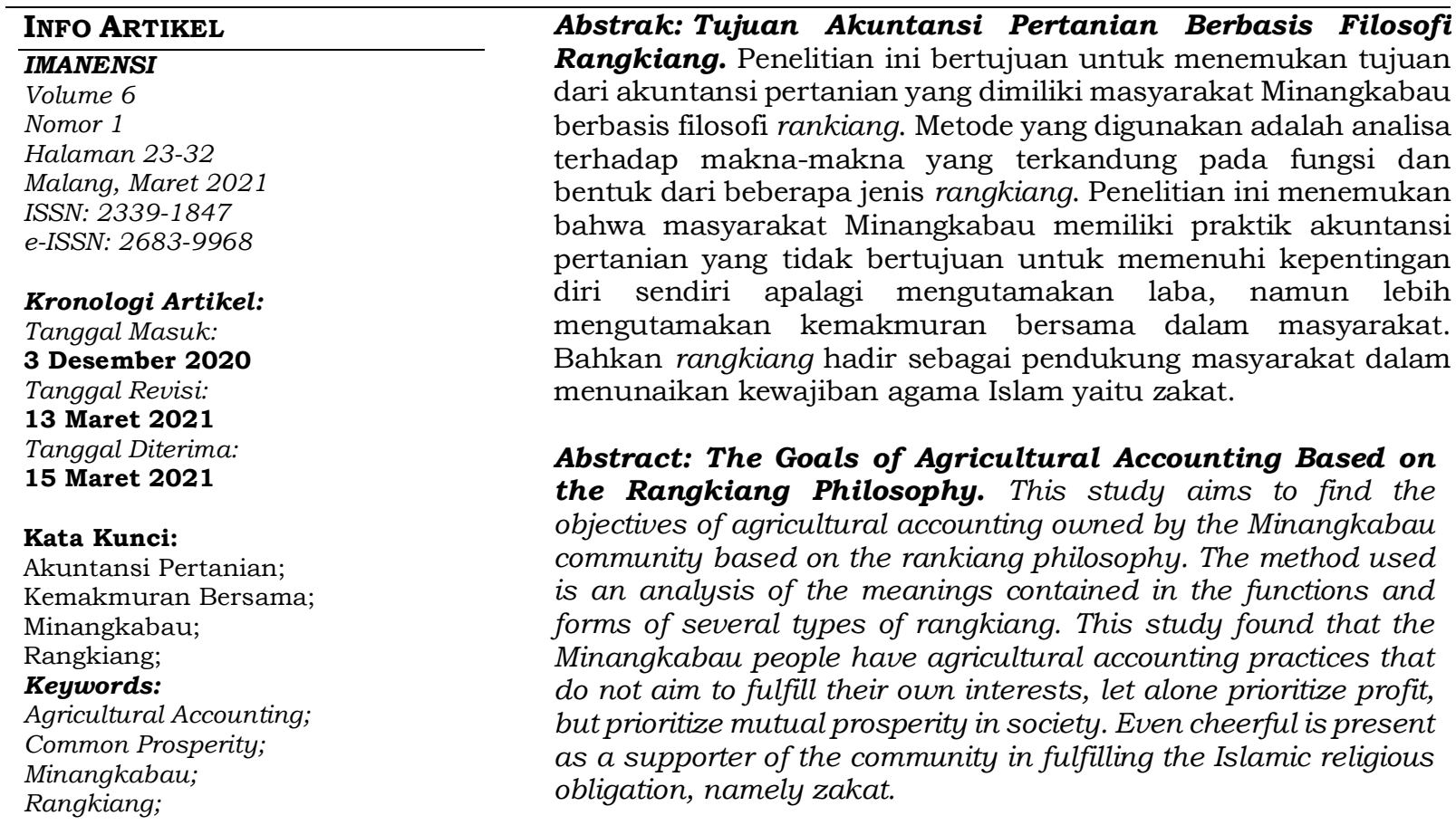

Rangkiang;

\begin{abstract}
The Goals of Agricultural Accounting Based on Rangkiang Philosophy. This study aims to find the community based on the rankiang philosophy. The method used actices that obligation, namely zakat.
\end{abstract}

Disitasi sebagai: Ath Thahira, K., dan Fernanda, D. (2021). Tujuan Akuntansi Pertanian Berbasis Filosofi Rangkiang. IMANENSI: Jurnal Ekonomi, Manajemen, dan Akuntansi Islam, 6(1), 23-33. https://doi.org/10.34202/imanensi.6.1.2021.23-33.

\section{PENDAHULUAN}

Praktik akuntansi di seluruh prosesi bertani padi di sawah tidak hanya berkenaan dengan aspek material saja, tetapi di dalam tahapan-tahapan bertani mengandung aspek akuntansi bernilai kesucian (religius) sekaligus sarat aspek kebudayaan (Mulawarman, 2019). Kami percaya bahwa praktik akuntansi muncul dari aktivitas pertanian yang suci, murni, diwarnai oleh nilai-nilai kebudayaan dan bebas dari kepentingan individu. Nilai-nilai inilah yang membuat akuntansi pada sektor pertanian zaman dahulu menciptakan petani-petani yang bertanggungjawab terhadap alam, masyarakat dan juga Tuhan. Praktik akuntansi bagi para petani 
tidak hanya berfungsi sebatas untuk menghitung materi dan keuntungan belaka, namun ada tanggung jawab yang lebih penting yang harus dipenuhi, yaitu tanggung jawab kepada Tuhan semesta alam, sehingga dalam satu waktu petani dapat berperan sebagai homo religius, homo economicus, dan juga homo socious (Kurniawan et al, 2014).

Penelitian mengenai akuntansi pertanian berbasis kearifan lokal sudah sering dilakukan (Kurniawan dkk, 2014; Rizaldi, 2012; Izzah, 2018). Penelitian-penelitian tersebut menemukan bahwa petani lokal, walaupun dari daerah yang berbeda tidak hanya menjadikan materi sebagai tujuan utama dalam aktivitas pertanian mereka, namun mereka selalu melibatkan nilai-nilai religius, seperti kejujuran, keadilan, keikhlasan dan tanggung jawab kepada Tuhan dalam segala aktivitas pertanian mereka. Beberapa penelitian sebelumnya menggali nilai-nilai adat dan agama dalam praktik akuntansi pertanian di daerah masing-masing, seperti penerapan nilai keadilan dalam sistem bagi hasil pertanian petani penggarap di Sidden Rappang, provinsi Sulawesi Selatan (Wahyuni, 2013) dan bagi hasil kebun karet pada masyarakat Kampar, provinsi Riau (Harkaneri, 2014). Bahkan ditemukan sebuah konsep melampaui laba dalam praktik akuntansi pertanian (Mulawarman, 2020).

Minangkabau dengan wilayah teritorialnya yang dihiasi oleh zona hijau ini tentu juga memiliki nilai-nilai kearifan lokal dalam praktek akuntansi pertaniannya, salah satunya yaitu rankiang. Rangkiang adalah unsur penting dalam praktik akuntansi pertanian masyarakat Minangkabau. Penggunaan rangkiang membantu mereka dalam mengalokasikan dan menyimpan persediaan padinya dengan baik. Bahkan, rangkiang juga digunakan sebagai media untuk memenuhi tanggung jawab sosial kepada masyarakat dan juga tanggung jawab agama. Rangkiang merupakan bangunan yang berfungsi sebagai tempat penyimpan berbagai hasil pertanian di Minangkabau khususnya padi sebagai makanan utama masyarakat. Rangkiang didirikan di depan rumah gadang dengan jumlah yang beragam disesuaikan dengan kebutuhan pemiliknya

Penelitian ini mencoba merumuskan tujuan dari akuntansi pertanian berdasarkan filosofi dan makna dari masing rangkiang (si tinjau lauik, si bayau bayau, si tangguang lapa, dan rangkiang kaciak). Hal ini perlu dilakukan untuk menyadarkan kembali masyarakat Minangkabau akan tujuan akuntansi pertanian sehingga walaupun secara fisik keberadaan rangkiang tidak ada lagi, namun praktik akuntansi berbasis rangkiang harus tetap hidup di kalangan masyarakat Minangkabau

\section{METODE}

Mempelajari makna yang terkandung dalam sebuah bangunan membutuhkan pendekatan dari ilmu arsitektur. Menurut ilmu arsitektur, proses desain bangunan yang mempertimbangkan kondisi iklim lokal, dilakukan dengan penggunaan teknik dan material lokal, serta dipengaruhi oleh aspek sosial, budaya, dan ekonomi masyarakat setempat dikenal dengan istilah arsitektur vernakular. Istilah arsitektur vernakular ini diperkenalkan pertama kalinya oleh Bernard Rudofsky pada tahun 1964 melalui pameran yang bertema "Architecture without Architects" di Museum of Modern Art (MoMA). Istilah vernacular berasal dari bahasa Latin, yaitu verna memiliki arti domestic, indigenous, native slave, atau home-born slave. Istilah ini dipilih oleh Rudofsky untuk mengklasifikasikan arsitektur lokal (umumnya berupa hunian) yang ditemukannya di berbagai belahan dunia yang selanjutnya dikenal oleh kalangan arsitektur sebagai "arsitektur tanpa arsitek".

Definisi terbaru dari arsitektur vernacular ini lebih dikaitkan dengan adanya hubungan antara bangunan dengan lokalitas, seperti yang dapat ditemukan dari beberapa referensi para akademisi yaitu “...a building designed by an amateur 
without any training in design" (Brunskill, 2000) dan "the purest definition of vernacular architecture is simple...it is architecture without architects" (Ladd, 2003), selanjutnya "Vernacular houses are born out of local building materials and technologies and an architecture that is climate-responsive and a reflection of the customs and lifestyles of a community". (Ravi S. Singh, 2006).

Arsitektur vernacular menurut Oliver (1997) dapat diidentifikasi melalui unsur-unsur; 1) bangunan tradisional yang dibangun sendiri atau komunitas masyarakat; 2) jenis bangunan original; 3) arsitektur yang berada dalam konteks lingkungan dan budaya masyarakatnya; 4) Bangunan yang dipengaruhi oleh kondisi lingkungan, sumber daya material, sistem struktur dan teknologi; 5) Aspek struktur sosial, sistem kepercayaan dan pola perilaku masyarakat mempengaruhi fungsi dan makna dari bangunan; 6) Bangunan lain ataupun tempat tinggal yang berhubungan dengan konteks lingkungan dan sumber daya lokal yang tersedia; 8) Pembangunan yang memanfaatkan teknologi tradisional; 9) Bangunan yang dibangun untuk memenuhi kebutuhan tertentu, mengakomodasi nilai-nilai, ekonomi dan cara hidup budaya lokal. Berdasarkan beberapa defenisi dan karakter yang telah disebutkan sebelumnya dapat disimpulkan bahwa rangkiang termasuk dalam kategori arsitek vernacular. Alasannya karena rangkiang dibangun oleh komunitas masyarakat lokal yang desainnya menyesuaikan kondisi iklim lokal, pembangunannya dilakukan dengan menggunakan teknik dan sumber daya lokal serta dipengaruhi oleh aspek sosial, budaya, dan ekonomi masyarakat lokal.

Metode pembacaan makna dari bangunan tradisional (rangkiang) dalam penelitian ini menggunakan dua unsur yang ada pada bangunan, yaitu fungsi dan bentuk. Rapoport (2006) menjelaskan terdapat beberapa faktor yang saling mempengaruhi bentuk arsitektur dengan budaya. Hasil studinya juga menekankan bahwa pemahaman terhadap makna merupakan intisari untuk mengetahui bagaimana hubungan makna dengan lingkungan karena makna dari sebuah arsitektur hanya dapat digali dengan menelusuri budaya masyarakat serta lingkungan sekitarnya. Moustafa (1988) menjelaskan bahwa makna dapat terungkap melalui fungsi dari elemen bentuk-bentuk, baik secara pragmatik maupun simbolik dan timbal balik.

Makna arsitektur dipengaruhi oleh konteks budaya yang berdasarkan pada ruang dan waktu. Oleh karenanya, pemhahaman arsitektur sebagai produk budaya memerlukan pemahaman terhadap masyarakat dan lingkungannya yang merupakan aspek yang penting dalam menemukan sistem-sistem tanda dan makna dari arsitektur tersebut. Pendapat ini juga didukung oleh Fauzi, dkk (2012) yang menekankan bahwa pengertian makna selalu berhubungan dengan fungsi dan bentuk. Oleh karena itu, hubungan antara fungsi, bentuk dan makna tidak dapat dipisahkan antara satu dengan yang lainnya karena ketiga unsur ini saling mempengaruhi melalui proses bolak-balik. Makna menjadi komponen utama yang mampu menjelaskan hubungan antara fungsi dan bentuk dari sebuah bangunan.

\title{
4. HASIL DAN PEMBAHASAN
}

\author{
Minangkabau, tanah nan den cinto \\ Pusako bundo, nan dahulunyo \\ Rumah gadong, nan sambilan ruang \\ Rangkiang baririk di halamannyo. \\ Jikok den kana hati den taibo \\ Tabayang bayang di ruang mato
}

Sepenggal lirik lagu "Minangkabau" ini cukup untuk untuk menggambarkan kerinduan kami akan kehidupan masyarakat Minangkabau di masa dahulu, rindu 
akan tanah yang menjadi tempat kami dilahirkan dan menghabiskan masa kecil kami, rindu melihat rumah gadang dengan gonjongnya dan rangkiang yang berdiri berjejer di halaman depannya.

Rumah Gadang bagi masyarakat Minangkabau tidak hanya berfungsi sebagai tempat tinggal saja, namun lebih dari itu, rumah gadang berperan sebagai lambang eksistensi keberadaan suatu kaum yang berada di bawah satu payung adat dan dipimpin oleh seorang penghulu (Marthala, 2013). Secara simbolis, Rumah Gadang juga merupakan salah satu dari beberapa unsur yang dikenal dengan istilah cahayo Nagari (cahaya nagari) atau hiasan nagari (Navis, 1986). Rumah Gadang biasanya selalu dilengkapi dengan halaman dan rangkiang. Pada umumnya, halaman rumah gadang dihiasi dengan tumbuhan-tumbuhan (pagar hidup) yang mencerminkan kehidupan, kesejahteraan dan kemakmuran penghuninya, sedangkan bentuk daun dan warna tumbuh-tumbuhan yang terdapat di halaman rumah gadang merupakam lambang keindahan dan cita rasa dari pemiliknya. Rangkiang adalah tempat penyimpan dari berbagai hasil pertanian terutama padi sebagai makanan utama. Rangkiang terletak didepan rumah gadang, jumlahnya beragam sesuai dengan yang diperlukan oleh pemiliknya.

Bangunan Rangkiang didirikan sebagai simbol ekonomi "kerakyatan" dan ekonomi "kegotong-royongan". Rangkiang Si Tinjau Lauik merupakan rangkiang dengan bentuk yang paling langsing dan biasanya berada pada posisi paling tengah. Rangkiang ini berisikan padi yang dipersiapkan untuk dijual. Selanjutnya, hasil penjualan dari padi tersebut digunakan untuk membiayai pengeluaran rutin atau membeli kebutuhan sehari-hari saat diperlukan. Hal ini berarti bahwa padi yang disimpan dalam Rangkiang Si Tinjau Lauik merupakan harta satu-satunya yang menjadi sumber penghasilan untuk menghidupi satu keluarga yang hidup dalam satu Rumah Gadang.

Rangkiang Si Bayau-Bayau merupakan rangkiang dengan pentuk yang paling gemuk dan memiliki enam tiang, posisinya berada di sebelah kanan Rumah Gadang dan berfungsi sebagai tempat penyimpanan padi yang digunakan untuk konsumsi atau kebutuhan makan sehari-hari dilengkapi dengan lauk pauk yang diperoleh dari hasil penjualan padi yang disimpan di Rangkiang Si Tinjau Lauik. Rangkiang Si Tangguang Lapa memiliki bentuk persegi dan memiliki fungsi khusus yaitu untuk pemenuhan tanggung jawab sosial dan pelaksanaan system ekonomi gotong royong. Padi yang disimpan dalam rangkiang ini juga dapat digunakan sebagai persediaan untuk musim paceklik ataupun gagal panen. Selain itu, padi ini juga dapat digunakan untuk menolong orang kampung lain yang sedang mengalami kesusahan dan kesulitan. Sayangnya, semangat membantu sesama dan gotong royong yang tercermin dalam fungsi rangkiang si tangguang lapa ini telah hilang karena masyarakat Minangkabau sudah mulai dipengaruhi oleh budaya Barat yang hidup secara individu.

Jenis yang terakhir yaitu Rangkiang Kaciak dengan bentuk yang lebih kecil, lebih rendah, dan tidak memiliki gonjong. Rangkiang ini berfungsi sebagai tempat menyimpan padi abuan yang merupakan padi yang digunakan untuk benih padi di musim yang akan datang dan sebagai modal yang digunakan untuk pengerjaan sawah berikutnya. Sehingga, persiapan untuk pengerjaan sawah untuk musim berikutnya sudah difikirkan dari masa panen saat ini agar pengerjaan sawah berikutnya dapat dikerjakan secara lancar dan tidak mengalami hambatan.

Keberadaan rangkiang tentu saja memiliki arti penting bagi masyarakat Minangkabau. Kami meyakini bahwa rangkiang bukanlah hanya sekedar tempat penyimpanan padi, namun lebih dari itu. Rangkiang memiliki makna yang dekat dengan pengelolaan harta dan pengelolaan harta berkaitan erat dengan akuntansi. Pengelolaan harta atau manajamen asset adalah ilmu yang digunakan untuk 
perolehan, perencanaan, pengelolaan dan pemeliharaan aset. Hampir sama dengan akuntansi yang memiliki peran penting terhadap keberlanjutan perusahaan di masa sekarang. Pada masa lalu rangkiang memiliki peran vital dalam mempertahankan kehidupan suatu kaum bahkan kaum lain di sekitarnya.

Saat ini, keberadaan rangkiang secara raga dan jiwa telah hilang di tengahtengah kehidupan masyarakat Minangkabau. Secara historis, masyarakat tradisional Minangkabau pada masa dahulu telah mengenal teknik pengurusan dalam membelanjakan harta benda yang mereka miliki melalui rangkiang dan sudah memikirkan kehidupan sosial dan tenggang rasa dalam kehidupan bermasyarakat. Kehidupan masyarakat Minangkabau secara gotong royong tidak hanya memikirkan kepentingan diri sendiri, namun juga memikirkan kondisi karib kerabat dan tetangga mereka yang sedang mengalami kesulitan. Kaum yang memperoleh kelebihan hasil panen dengan senang hati memberikan kelebihan tersebut kepada kaum yang mengalami kekurangan atau kesulitan (tempat si miskin salang-tenggang, penangkal lapar dalam kampung, ketika musim tanggung tiba).

Kebudayaan saling tolong menolong telah menjadi ciri dari kehidupan sosial masyarakat tradisional. Namun sayangnya, praktik akuntansi pertanian ini tidak ditemukan lagi di kehidupan masyarakat minangkabau modern. Kebiasaan masyarakat tradisional yang membagi hasil panennya menjadi beberapa bagian disesuaikan dengan banyaknya Rangkiang yang kemudian digunakan sesuai dengan fungsi masing-masing Rangkiang. Hal ini membuktikan bahwa sistem ekonomi agraris yang dimiliki oleh masyarakat Minangkabau tradiosional sudah sangat teratur. Sistem yang lahir dari kearifan budaya lokal yang menyatu dengan alam yang telah hilang tergerus oleh perkembangan modernitas yang lebih mengedepankan semangat individualisme.

\subsection{Makna Filosofis dari Fungsi Rangkiang}

Minangkabau adalah salah satu etnis di Indonesia yang menjadikan alam sebagai pedoman kehidupannya. Masyarakatnya yang tinggal di lingkungan agraris mendorong mayoritas masyarakatnya berprofesi sebagai petani. Sehingga tidak mengherankan jika kata petatah-petitih yang digunakan dalam kegiatan-kegiatan adat sangat bernuansa alam agraris pedesaan. Salah satu contoh petatah-petitih yang menggunakan kata-kata bernuansa alam agraris adalah sebagai berikut:

Laweh alamnyo bakeh tagak Sawah batumpak di nan data Ladang babidang di nan lereang Sawah bajanjang banda buatan Sawah ladang labuah nan pasa Taranak kambang padi manjadi Buah jaguang maampai suto Padi masak jaguang maupiah Lah masak padi di sawah Padi ladang manguniang pulo Ladang tabu manyintak rueh Pisang badukuang di tandannyo Antimun mangarang bungo Batang labu marantang tali Buah taruang ajun-ayunan Buah Lado mambintang timue Buah kacang taji-tajian Anak rancak minantu malin (Madjo-Indo, 1999)
Luas alamnya tempat berdiri Sawah bertumpuk di tanah yang datar Ladang berbidang di lereng Sawah berjenjang irigasi buatan Sawah ladang jalan yang pasar Ternak berkembang padi menghasilkan Buah jagung menghampai suto Padi masak jagung mengupih Sudah masak padi di sawah Padi ladang menguning pula Ladang tebu menyintak ruas Pisang didukung di tandannyo Mentimun mengarang bunga Batang labu merantang tali Buah terong ajun ayunan Buah lada membintang timur Buah kacang taji-tajian Anak cantik menantu malin 
Petatah petitih di atas memperkuat keyakinan kita bahwa masyarakat Minangkabau sangat dekat dengan kegiatan pertanian. Penggunaan kata alam, sawah, ladang, ternak, padi, jagung, tebu, pisang, mentimun, labu, terong lada, dan kacang adalah wujud dari peradaban masyarakat Minangkabau yang mayoritas hidup sebagai Petani.

Rangkiang ditata di halaman rumah gadang secara berjejer agar terlihat harmonis berdiri berdampingan dengan rumah gadang. Rangkiang menjadi lambang kemakmuran bagi anggota kaum dan sebagai alat yang digunaakan dalam pengaturan harta benda. Padi yang disimpan dalam rangkiang disesuaikan dengan kebutuhan kaum, ada rangkiang yang padinya digunakan untuk konsumsi anggota kaum, ada juga rangkiang yang padinya digunakan untuk kebutuhan kaum kerabat, selain itu juga ada padi yang dipersiapkan untuk keperluan upacara adat, kenduri, zakat dan sedekah, separti yang tertuang dalam pepatah:

Rangkiang tigo sahajaja, kapuak gadang salo manyalo, kapuak kaciak salek manyalek, di tapi sitinjau lauik, panagua dagang kamalaman, di tangah sibayau-bayau, lumbuang makanan patang pagi, di pangka sitangka lapa, tampek nan miskin salang tenggang, panangka lapa dalam kampuang, kutiko musim gantuang tunggu.

(Rangkiang tiga sejajar, kapuk besar sela menyela, kapuk kecil selip menyelip, di tepi si tinjau laut, peninjau pincalang masuk, penegur dagang ke malaman, di tengah si bayau-bayau, lumbung makanan petang-pagi, di pangkal si tangkal lapar, tempat si miskin selang-tenggang, penangkal lapar dalam kampung, ketika musim gantung tiba).

Setiap jenis rangkiang memiliki kegunaan yang berbeda seperti; rangkiang si tinjau lauik yang digunakan untuk menyimpan padi untuk persiapan kebutuhan upacara adat, rangkiang si bayau-bayau yang berfungsi untuk menyimpan keperluan konsumsi sehari hari dan rangkiang si tangka lapa yang digunakan untuk mempersiapkan padi yang diperuntukkan dalam memenuhi tanggung jawab sosial seperti zakat dan sedekah. Rangkiang yang dulu selalu berdiri tegak mengelilingi Rumah Gadang tentu saja tidak hanya berfungsi hanya sebagai tempat penyimpanan padi. Bangunan ini pasti memiliki makna dan filosofi penting dalam kehidupan masyarakat Minangkabau.

\subsection{Makna Rangkiang Si Tinjau Lauik}

Rangkiang si tinjau lauik (si tinjau laut) digunakan sebagai tempat menyimpan padi yang nantinya dapat dijual dan digunakan untuk membeli barang atau keperluan rumah tangga yang tidak dapat dibuat sendiri. Selain itu, padi ini juga dipersiapkan untuk kebutuhan adat serta dapat digunakan juga untuk menyambut tamu dari luar yang datang ke kampung.

\section{Rangkiang tagak sajaja \\ Di tangah sitinjua lauik \\ Panjapuik si dagang lalu Paninjau pincalang masuak}

Petatah petitih di atas dapat dipahami bahwa fungsi rangkiang si tinjau lauik adalah sebagai tempat penyimpanan hasil panen yang boleh dijual dan kemudian digunakan untuk membiayai keperluan sehari-hari Rumah Gadang. Jika dikaitkan 
dengan praktik akuntansi, hal ini sama dengan yang biasanya kita kenal dengan pos pengeluaran (expenditure).

\title{
4.3 Makna Rangkiang Si Bayau-Bayau
}

Rangkiang ini merupakan jenis rangkiang yang berfungsi untuk menyimpan padi yang digunakan untuk pemenuhan kebutuhan konsumsi (makan) sehari-hari. Rangkian ini memiliki bentuk yang lebih gemuk dengan 6 (enam) tiang dan terletak di bagian kanan rumah gadang.

\section{Di kanan si bayau-bayau}

Lumbuang makan patang pagi

Petatah-petitih di atas menjelaskan bahwa rangkiang si bayau-bayau memiliki fungsi sebagai tempat penyimpanan yang digunakan untuk pemenuhan kebutuhan pangan (konsumsi) penghuni Rumah Gadang.

\subsection{Makna Rangkiang Si Tangguang Lapa}

Rangkiang ini dipersiapkan untuk menghadapi hal-hal yang tidak diinginkan. Rangkiang ini menjadi penolong disaat mengalami kesulitan, seperti musim paceklik ataupun gagal panen. Rangkiang ini tidak hanya menjadi penolong bagi pemilik rumah gadang di masa kesulitan, namun juga menjadi penolong bagi masyarakat sekitar yang juga mengalami kesulitan seperti kekurangan makanan. Rangkiang ini berbentuk persegi yang berdiri di atas 4 tiang dan terletak di sebelah kiri rumah gadang.

\author{
Di kiri sitenggang lapa \\ Tampek si miskin salang tenggang \\ Panolong urang kampuang \\ Di musim lapa gantuang tungku
}

Petatah petitih tersebut menjelaskan bahwa Rangkiang Si tangguang lapa dipersiapkan khusus untuk memenuhi tanggung jawab sosial kaum pemilik rumah gadang seperti membantu orang-orang yang membutuhkan. Selain itu, hasil panen yang disimpan di rangkiang ini juga dapat digunakan untuk memenuhi kewajiban agama seperti membayar zakat dan sedekah. Tujuan yang paling penting dari rangkiang ini adalah sebagai persiapan dalam menghadapi bencana alam. Jika dikaitkan dengan ilmu ekonomi saat ini, maka fungsi rangkiang ini sangat erat kaitannya dengan pemenuhan tanggung jawab agama dan sosial (Religious and Social Responsibility), ketahanan pangan (Food Security) dan penanggulangan bancana alam (Disaster Mitigation).

\subsection{Makna Rangkiang Kaciak}

Kaciak berarti kecil. Nama kecil digunakan untuk rangkiang ini karena rangkiang kaciak memang dibuat dengan bentuk paling kecil dari yang lainnya. Rangkiang kaciak ini digunakan sebagai tempat menyimpan padi abuan (benih). Jika tiba saatnya musim bertanam, padi abuan ini diambil untuk disemai. Rangkiang kaciak ini biasanya terletak diantara ketiga rangkiang lainnya yang lebih besar.

\section{Lumbuang kaciak salo-manyalo \\ Tampek manyimpan padi abuan}

Keberadaan rangkiang kaciak manjadi sangat penting karena berhubungan dengan usaha untuk menjaga keberlanjutan aktivitas pertanian di masa yang akan datang. Konsep ini sangat sesuai dengan yang kita kenal dalam akuntansi yaitu 
konsep keberlanjutan (Sustainability). Makna filosofis yang dapat ditemukan dari fungsi masing-masing rangkiang berkaitan dengan praktik akuntansi pertanian digambarkan dalam Tabel 1.

Tabel 1. Makna Filosofi Rankiang Berdasarkan Fungsi dalam Akuntansi Nama Rangkiang Fungsi

Fungsi dalam Akuntansi

Si Tinjau Lauik

Si Bayau-bayau

Si Tangka Lapa

Rankiang Kaciak
Dipersiapkan untuk membiayai kebutuhan sehari-hari dan kegiatan adat serta menjamu tamu yang datang dari luar.

Memenuhi kebutuhan konsumsi seharihari keluarga dan kaum

Zakat dan sedekah, ketahanan pangan, fungsi sosial (memberantas kemiskinan), dan persiapan untuk kondisi darurat

Keberlanjutan aktivitas pertanian di masa yang akan datang
Expenditure

Consumption

Religious and Social Responsibility, Food Security \& Disaster Mitigation

Sustainability

\subsection{Perumusan Tujuan Akuntansi Pertanian Berdasarkan Filosofis Rangkiang}

Umumnya bentuk masing-masing rangkiang hampir sama, perbedaan hanya di ukuran atau jumlah tiang yang menjadi penyangga dari rankiang. Namun, bagianbagian penting dari setiap rangkiang biasanya hampir sama (lihat Gambar 1). Bangunan rangkiang yang berjejer di halaman Rumah Gadang ini memiliki makna penting. Atap rangkiang yang berbentuk gonjong diibaratkan seperti harapan untuk mencapai Allah SWT. Dinding yang terbuat dari potongan anyaman bambu melambangkan kekuatan dan utilitas masyarakat Minangkabau yang terbentuk ketika tiap individu menjadi bagian masyarakat yang lebih besar dan tidak berdiri sendiri. Lantai yang berbentuk panggung dan berjarak dari tanah bertujuan untuk padi dari tanah yang lembap.

Rangkiang dibuat berbentuk trapesium terbalik dengan tujuan untuk menghindari rangkiang dari terpaan air hujan secara langsung. Selain itu, salah satu hal unik yang dimiliki rangkiang adalah posisi pintunya yang terletak di dinding atap. Desain pintu yang terletak di dinding atap ini bertujuan agar pemilik rumah gadang tidak bisa mengambil padi dari dalam rangkiang dengan gampang, sehingga padi di dalam rangkiang hanya diambil ketika diperlukan saja. Hal ini mencerminkan karakter masyarakat Minangkabau yang ekonomis, menghargai hasil panen, mengajarkan untuk berhemat dan tidak mudah menjual padi selain untuk kepentingan mendesak.

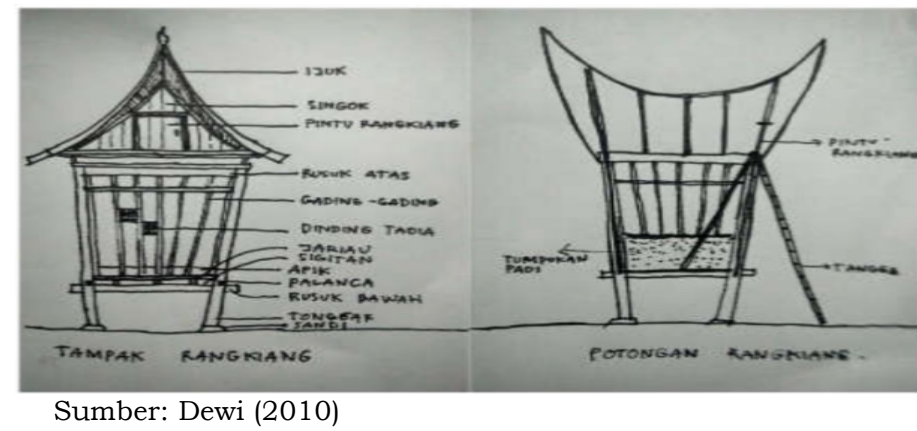

Gambar 1. Bentuk Rankiang 
Makna filosofis dari fungsi dan bentuk rangkiang, pada akhirnya dapat dirumuskan tujuan akuntansi pertanian berbasis filosofi rangkiang adalah melakukan aktivitas pengelolaan dan penyimpanan hasil pertanian dalam rangka mendekatkan diri kepada Allah SWT. Cara yang dilakukan memanfaatkan dengan sebaik baiknya hasil pertanian untuk kebutuhan pangan dan keperluan sehari-hari kaum keluarga. Memenuhi kewajiban agama dengan mengeluarkan zakat dan sedekah dari hasil pertanian, melaksanakan tanggung jawab sosial dengan menyediakan bagian dari hasil pertanian untuk membantu masyarakat yang berada dalam kekurangan. Mempersiapkan hasil pertanian untuk menjaga ketahanan pangan dalam menghadapi musim paceklik atau bencana alam, serta menyisihkan hasil pertanian yang akan dijadikan benih untuk keberlanjutan aktivitas pertanian di masa yang akan datang".

\section{SIMPULAN}

Tujuan akuntansi pertanian dengan filosofi rankiang diharapkan dapat menyadarkan kembali masyarakat Minangkabau akan makna-makna penting dari bangunan rangkiang agar terus diabadikan dalam praktik akuntansi pertanian saat ini. Walaupun secara fisik bangunan rangkiang sudah sangat jarang ditemukan, namun makna filosofis dari keberadaan rangkiang seharusnya terus dijaga dan hidup di hati masyarakat agar tercapai tujuan akuntansi pertanian yang dapat mewujudkan manusia-manusia yang bertanggung jawab terhadap Allah, alam, agama dan masyarakat sekitarnya.

Kajian mengenai praktik akuntansi pertanian di Minangkabau dapat ditelusuri lebih lanjut lagi karena Minangkabau sangat dekat dengan alam, sehingga banyak filosofi kehidupannya yang bersumber dari alam. Masyarakat Minangkabau juga sangat dekat dengan aktivitas pertanian, sehingga tidak mengherankan jika ukiran-ukiran, tarian-tarian, petatah-petitih yang dihasilkan mayoritas terinspirasi dari aktivitas pertaniannya. Keterbatasan referensi yang diperoleh membuat kajian mengenai filosofis rangkiang ini belum terlalu komprehensif, namun dapat menjadi saran untuk pengembangan kajian di masa yang akan datang.

\section{REFERENSI}

Brunskill, Vernacular Architecure: An Illustrated Handbook, (Faber \& Faber, 4th ed, 2000), pp.27-28

Dewi (2010). Arsitektur Vernakular Minangkabau (Kajian Arsitektur dan Eksistensi Rumah Gadang dilihat dari pengaruh dan perubahan Budaya). Skripsi. Universitas Indonesia.

Fauzy, B, Antariksa, P. Salura. (2012). Memahami Relasi Konsep Fungsi, Bentuk dan Makna Arsitektur Rumah Tinggal Masyarakat Kota Pesisir Utara di Kawasan Jawa Timur, Kasus Studi: Rumah Tinggal di Pecinan Kampung Karangturi dan Kampung Jawa Sumber Girang, Lasem. Seminar Nasional Dies Jurusan Arsitektur Universitas Kristen Petra "Towards Emphatic Architecture" (pp. -). Surabaya: Jurusan Arsitektur Universitas Kristen Petra

Harkaneri. (2014). Memahami Praktek Bagi-Hasil Kebun Karet Masyarakat Kampar Riau. Jurnal Al-Iqtishad, Volume 2(10),14-38.

Izzah, D. (2018). Kearifan Lokal pada Sistem Bagi Hasil Petani Cengkeh di Bobaneigo, Halmahera Utara Maluku Utara. Tesis. Program Magister Akuntansi Pascasarjana FEB Universitas Brawijaya Malang.

Kurniawan et al. (2014). Biological Assets Valuation reconstruction: A Critical Study of IAS 41 on agricultural accounting in Indonesian Farmers. International Conference on Accounting Studies. 18-19 August, Kuala Lumpur, Malaysia

Ladd, Nick. 2003. What Is Vernacular Architecture? ARCH 420 - September 30. 
Madjo-Indo. (1999). Kato Pusako Papatah, Patitih, Mamang, Pantun Ajaran dan Filsafat Minangkabau, PT Rora Karya, Jakarta.

Marthala, A. E., (2013). Rumah Gadang Kajian Filosofi Arsitek Minangkabau

Moustafa, A. (1988). Architectural Representation and Meaning: Towards a Theory of Interpretation. Massachusetts: The Massachusetts Institute of Technology.

Mulawarman, A. D. (2019). Akuntansi Pertanian: A Prophetic Legacy. Penerbit Peneleh.

Mulawarman, A. D. (2020). Jalan Laba Petani: Falāh al-Fallāh. Jurnal Riset dan Aplikasi: Akuntansi dan Manajemen, 4(2), 213-222.

Navis, A.A. (1986). Alam Takambang Jadi Guru, Adat dan Kebudayaan Minangkabau. Jakarta.

Oliver, Paul (ed.) 1997 Encyclopedia of Vernacular Architecture of the World. 3 vols. Cambridge: Cambridge University Press.

Rapoport, Amos. 2006. Vernacular Design as a Model System. In Asquith, Lindsay and Marcel Vellinga (eds). Vernacular Architecture in the Twenty-First Century. Theory, Education and Practice. London and New York: Taylor \& Francis.

Ravi S. Singh. 2006. Defining „Vernacular"e: Changing Vernacular Houses around Varanasi, UP (India)Durckheim 1925 Les formes elementaires de la vie religieuse. Felix Alcan Paris

Rizaldy, N. (2012). Menemukan Lokalitas Biological Asstes: Pelibatan Etnografis Petani Apel. Jurnal Akuntansi Multiparadigma. Vol.3, No.3. hal 334-501.

Wahyuni, A. S. (2013). Penyesuaian Konsep Bagi Hasil Adat-Syariah. Jurnal Akuntansi Multiparadigma, 4(3), 467-478. 